\title{
Modelos de intermedialidad en la adaptación cinematográfica del teatro homosexual en el cine de Pedro Almodóvar*
}

\author{
INTERMEDIALITY MODELS IN FILM ADAPTIONS OF HOMOSEXUAL DRAMA IN \\ PEDRO ALMODÓVAR'S CINEMA \\ MODELOS DE INTERMEDIALIDADE NAS ADAPTAÇÕES CINEMATOGRÁFICAS \\ DO TEATRO HOMOSSEXUAL NO CINEMA DE PEDRO ALMODÓVAR
}

\section{Mario de la Torre Espinosa**}

Cuadernos de Música, Artes Visuales y Artes Escénicas

/ Volumen 13 - Número 1 / Enero - Junio de 2018

/ ISSN 1794-6670/ Bogotá, D.C., Colombia / pp. 117-133

Fecha de recepción: 5 de diciembre de 2016

Fecha de aceptación: 9 de febrero de 2017

Disponible en línea: 6 de diciembre de 2017

doi:10.11144/javeriana.mavae13-1.mdid

Artículo de investigación resultado de la tesis doctoral La teatralidad en el cine: una aproximación polisistémica al cine de Pedro Almodóvar.

Licenciado en Documentación, diplomado de Estudios Avanzados, Teoría de la Literatura y del Arte y Literatura Comparada, magíster en Bioética y Humanización de la Asistencia y doctor en Teoría de la Literatura y del Arte y Literatura Comparada por la Universidad de Granada. Profesor de Comunicación Audiovisual en la Universidad Complutense de Madrid, la Escuela Universitaria TAI (Universidad Rey Juan Carlos), el Centro Universitario San Isidoro (Universidad Pablo de Olavide) y la Universidad de Cádiz en el área de Teoría de la Literatura y Literatura Comparada. 


\section{Resumen}

El cine de Pedro Almodóvar es complejo y pleno de intertextos, siendo el teatro una de sus fuentes de recursos principales. El objetivo de este trabajo es analizar cómo en su filmografía ha ido adaptando las obras de dramaturgos que podrían ser englobados dentro de la categoría de queer drama, caracterizado por una focalización novedosa donde el hombre se convertía en objeto del deseo. Utilizando la narratología fílmica y la teoría queer, se ha analizado cómo obras de Lorca, Feydeau, Tennessee Williams o Jean Cocteau, con una sensibilidad queer latente en unos y evidente en otros, sirven así de modelo para parte de su cine. Como conclusión, se puede vislumbrar una línea de continuidad entre los modos de representación de las sexualidades "no normativas" en todos estos autores, que enlazan con la categoría de enunciación paranoica formulada por Alberto Mira. Queda demostrado así cómo estas rupturas con el modo de representación institucional, según la definición de Nöel Burch, manifestadas en la cinematografía almodovariana, tienen uno de sus hipotextos principales en el teatro homosexual.

Palabras claves: cine queer; teatro queer; narratología; adaptación cinematográfica; cine español; Pedro Almodóvar

\section{Abstract}

Pedro Almodóvar's cinema is complex and full of intertexts, and theatre is one of its principal resources. The goal of this article is analyze how have been adapted into his filmography the works of playwrights who are considered into the category of Queer Drama, with a new focalization where the man becomes an object of desire. Using film narratology and queer theory, it has been analyzed how plays of Lorca, Feydeau, Tennessee Williams or Jean Cocteau, with a latent or evident queer sensitivity, are used as models for part of his cinema. In conclusion, we can see in all these authors a continuity in the representation of "non-normative" sexualities, which links with the paranoid enunciation stated by Alberto Mira. Thus, it is evidenced how this ruptures with the institutional mode of representation, as defined by Nöel Burch and that are visible in the almodóvarian filmography, have in the homosexual theatre one of its main hypotexts

Keywords: arts; queer cinema; queer drama; narratology film adaptation; spanish cinema; Pedro Almodóvar

\section{Resumo}

O cinema de Pedro Almodóvar é complexo e cheio de in tertextos, sendo uma de suas fontes principais o teatro. O objetivo deste trabalho é analisar como, na sua filmografía, foram adaptadas as peças teatrais de dramaturgos que poderiam ser englobados dentro da categoria de Queer Drama, marcado por uma nova visão onde os homens são convertidos em objeto de desejo. Usando a narratologia fílmica e a teoria queer, foi analisado como obras de Lorca, Feydeau, Tennessee Williams ou Jean Cocteau, com uma sensibilidade queer latente numos e evidente em outros, atua como modelo para parte de seu cinema. Em conclusão, se observa uma linha de continuidade entre os modos de representação das sexualidades "não normativas" em todos estes autores, que ligam com a categoria de enunciação paranoica apresentada por Alberto Mira. Desta maneira é demonstrado como estas rupturas, com o modo de representação institucional, segundo a definação de Nöel Burch presentes na cinematografia almodovariana, tem um de seus hipotextos principais no teatro homossexual.

Palavras chave: cinema queer, teatro queer, narratología; adaptação cinematográfica; cinema espanhol; Pedro Almodóvar 


\section{INTRODUCCIÓN (EL TEATRO QUEER)}

El trato paródico del teatro que se puede observar en las primeras películas de Pedro Almodóvar se va diluyendo a medida que su obra adquiere un tono más trágico. Comenzamos a encontrar así la citación de obras pertenecientes a autores extranjeros: en La ley del deseo, contemplamos una puesta en escena de La voz humana, de Jean Cocteau; en Todo sobre mi madre, la obra Un tranvía llamado deseo, de Tennessee Williams; y en Hable con ella, las piezas Café Müller y Masurca fogo, de Pina Bausch. Pero no solo encontramos ejemplos foráneos, sino que la propia escena española se hace presente con una recreación de la obra Haciendo Lorca, de Lluís Pasqual. El hecho de acudir a estos grandes nombres de la escena del siglo XX demuestra una toma de consciencia sobre la historia del arte escénico, dado que los autores no parecen haber sido escogidos al azar.

El título de este trabajo hace mención expresa al teatro queer, y en torno a este concepto trazamos nuestro objetivo principal. Sin querer trazar el estado de la cuestión, vamos a demostrar cómo gran parte de las obras o modelos teatrales que se reproducen en la obra de Almodóvar participan de esa sensibilidad homosexual o enunciación paranoica de la que habla Alberto Mira (1994), basada en la edificación de una dramaturgia en torno al deseo que se distancia del modo de representación heterosexual. Esto no implica que el autor o los personajes que aparezcan en escena sean identificados como homosexuales, sino más bien conlleva que esté presente una serie de rasgos -explícitos o latentes_ que marcan ese carácter queer citado: 'Queer', a term commonly used to deride and vilify same-sex desiring people, was reclaimed by Queer Nation and others as a umbrella to celebrate, rather than castigate, difference from the 'norm' at a time when the oppressiveness and implicit violence of that norm was clear and undeniable"1 (Hall 2003, 53-4).

${ }^{1}$ Esta definición de Donald E. Hall —que nos sirve para establecer el marco teórico usado en este trabajo, los queer studies, junto con la narratología fílmica- hace referencia a un proceso histórico concreto, a la reivindicación política de lo queer acaecida en la década de $1990 .{ }^{2}$ En un momento de reivindicación, lo gay saldría de la contracultura norteamericana, pasando de la clandestinidad a ocupar, poco a poco, y no sin pocas reticencias, una visibilidad impensable años atrás. El discurso homosexual, latente en diferentes manifestaciones artísticas mainstream, se hacía patente al fin.

Volviendo al mundo de la escena, han sido varios los investigadores que han tomado el teatro queer como objeto de estudio y así lo han establecido como una categoría diferenciada de las otras formas teatrales. Entre las características que marcan su idiosincrasia, Alfonso Ceballos Muñoz señala tres: "La exhibición del cuerpo masculino desnudo, la articulación estético-política del camp y el discurso del sIDA" $(2004,25)$. Si bien esta definición de elementos es muy reductora, ya que circunscribe este teatro a la década de 1980, cuando el sida era una realidad muy mediatizada, las otras dos características nos son muy pertinentes. ${ }^{3}$

La primera de ellas reflexiona acerca de la conversión del cuerpo masculino en objeto de deseo rompiendo con una tradición heterosexual que hacía lo propio con el femenino. Si bien la censura - social o política - impuso siempre su yugo sobre este aspecto por tratarse de un comportamiento sexual "anormal," los autores dramáticos encontraron diferentes estrategias para hacerlo notar sin que desembocara en represalias de ningún tipo. Entre ellas, el desplazamiento del deseo de la focalización masculina a otra femenina, de manera que será ahora una 
mujer quien sienta esa atracción erótica, vehiculizándose el deseo homosexual a partir de la mirada de un personaje femenino (Mira 1994, 156). Estaríamos hablando, por ejemplo, de la atracción que siente Blanche Dubois por Stanley en Un tranvía llamado deseo, de Tennessee Williams. O la de Adela y Angustias por Pepe el Romano en La casa de Bernarda Alba, por poner un ejemplo de nuestra tradición teatral. ${ }^{4}$

El segundo elemento que nos interesa de la definición de Ceballos Muñoz hace referencia a la articulación de lo camp en la práctica teatral. Para intentar aclarar este aspecto, nos es necesario acudir al ensayo de Susan Sontag Notes on camp (1964). Al comienzo del escrito, la autora neoyorquina intenta definir su esencia exponiendo dos interesantes líneas de interpretación: "Es el amor a lo no natural: al artificio y la exageración. Y lo camp es esotérico: tiene algo de código privado, de símbolos de identidad incluso, entre pequeños círculos urbanos" $(1964,355)$. La primera parte hace mención a comportamientos "anormales", algo que se podría asociar fácilmente a las sexualidades Ilamadas "disidentes", presentes tras estas propuestas escénicas y, hasta hace bien poco, bajo la forma de latencia. El áspero ambiente sociocultural en el que se desarrollaron estas formas culturales, intolerante con cualquier conducta que discrepara de lo establecido por la tradición, provocaba esta anómala expresión de la propia sexualidad, sometida al artificio desde el momento en que debía ser camuflada bajo fórmulas que posibilitasen su comunicación pública sin consecuencias negativas, o bien bajo la forma de reprobación, o bien la más dura de castigo. De esto deriva que parte de las obras queer, hasta prácticamente finales de la década de 1980, contaran con un código privado, compartido por un grupo que tenía unas mismas claves hermenéuticas; un colectivo homosexual -o afín a este- que era conocedor de esos símbolos de identidad a los que hacía mención Sontag. Esta mostración —o, mejor dicho, ocultación parcial— de la homosexualidad en el escenario, o queer closet drama, según el término de Nicholas Salvato (2010), puede ser entendida a su vez como una reteatralización de la identidad sexual, donde lo camp es perceptible: se "pone de manifiesto la teatralidad de los roles sexuales y se amolda perfectamente a una identidad gay construida" (Ceballos Muñoz 2004, 160).

En este sentido, son, sin lugar a dudas, reveladores las declaraciones de Alan Sinfield al comienzo de su obra Out on Stage: Lesbian and Gay Theatre in the Twentieth Century (1999). A la hora de justificar el tema de su monografía, referida al ámbito anglosajón, alude, en primer lugar, al poder del teatro, que hizo que el contexto y subtexto homosexual -interpretable como un código privado camp, según Sontag - hubieran recibido siempre una especial atención por parte de los Gobiernos y sus organismos de control. Estas estructuras de poder han actuado, o bien para censurar aquellos contenidos que iban en contra de sus preceptos ideológicos, o bien, en una etapa posterior, para apoyarlos en el caso de que reforzaran su discurso progresista. ${ }^{5}$ Si bien es llamativa esta función sociológica del teatro, es el segundo elemento del que deja constancia Sinfield el que nos resulta especialmente atractivo, fundamentalmente, por la relación que se puede establecer con lo camp: "Second, theatre and theatricality have been experienced throughout the twentieth century as queer" (segundo, el teatro y la teatralidad han sido vividos durante todo el siglo XX como queer) $(1999,1)$. El autor inglés parte de la convicción de que el teatro ha sido en el siglo XX un refugio para las diferentes identidades sexuales. Para justificarlo, realiza un análisis diacrónico acudiendo a diferentes fuentes de la tradición teatral anglosajona que se remonta, incluso, a los inicios del siglo XVII. 
La historia del teatro gay en nuestro siglo pasado arranca con una idea moderna de homosexualidad personificada en la figura de Oscar Wilde. Suponía una forma de disensión respecto de la moral tradicional y, por tanto, una amenaza al orden preestablecido. La represión ejercida contra las formas culturales derivadas de este fenómeno provocó que inevitablemente la latencia se convirtiera en la única forma de subsistencia de la diversidad sexual en escena. Esta situación se prolongó durante décadas, aunque se revertiría con una mayor visibilidad en el ambiente contracultural que comenzaría a desarrollarse a mediados del siglo pasado. Las revueltas de 1969 de Stonewall supusieron un giro reivindicativo para la comunidad LGBT (lesbianas, gais, transexuales y bisexuales), con su consecuente reflejo en el mundo de la escena: la reclamación de la identidad homosexual se convertía en legítima. Con el tiempo, esta situación derivaría en varias formas de expresión, ${ }^{6}$ pasando finalmente a ser un discurso teatral plenamente integrado en el mainstream, que dio lugar, incluso, a veces a una visión autocomplaciente que niega un pasado opresor.

\section{DE LAS FARSAS DE FEYDEAU A LOS MELODRAMAS DE TENNESSEE WILLIAMS}

Dentro de esta línea interpretativa, que enlazaría con la sensibilidad camp, hay que observar la presencia a finales del siglo XX del teatro de Georges Feydeau como modelo operativo en el repertorio cultural español. Almodóvar, acerca de los modelos del teatro en su cine, ha citado al autor francés como uno de los más decisivos (citado en Strauss 2000, 76), aludiendo, en concreto, al ritmo y la comicidad de sus farsas. El uso de este modelo es especialmente notable en obras como Mujeres al borde de un ataque de nervios o Los amantes pasajeros, debido, esencialmente, a su mediación a través del cine, es decir, a la conversión de la farsa teatral en la screwball comedy hollywoodiense - véase en este proceso de transferencia de normas el caso de Lubitsch (Brewster 2001)

El autor francés, de gran fama por sus comedias de principios del siglo $X X{ }^{8}$ es considerado uno de los padres de la farsa como género teatral. La velocidad con la que se suceden los acontecimientos en sus obras - "Situational humor demands this speed and so does much of the humor in the dialogue" (el humor situacional exige esta velocidad y aún más en el humor de los diálogos) (Casmus 1980, 463) — y y el humor que se deriva de ello, son algunos de los rasgos distintivos de su teatro, marcado en su representación escénica, además, por una enérgica fisicidad preinscrita ya en el texto dramático (Parshall 1981). Esta aceleración de la acción permite que el espectador asuma como lógicos algunos giros argumentales que desde otro punto de vista serían inaceptables. La comedia, como elemento distanciador, también facilita este hecho:

Perhaps Georges Feydeau's most remarkable talent was for making the illogical seem perfectly sound. Disorder and irrationality acquire validity in his plays, undisturbed by the laws of probability or the insights of analysis. The farcical devices which fill Feydeau's comedies make this possible ${ }^{2}$ (Devine 1986, 22).

Asociado a Eugène Labiche como los dos grandes nombres del teatro de vodevil heredero de la farsa decimonónica francesa, su teatro ha ejercido influencia sobre numerosos autores dramáticos. A pesar de su éxito comercial, y de lo denostado de este subgénero de la comedia teatral, ${ }^{9}$ ambos autores han sido reivindicados como portadores de un mensaje trascendente al prisma cómico que determina formalmente sus producciones, sintomático del colapso moral de una sociedad burguesa decadente, en el que lo irrisorio opera en calidad de exorcismo del ritual social (Ramos Gay, 2003). 
El hecho de que a la hilarante sucesión de acontecimientos le acompañe una amarga reflexión sobre el sentido de la vida ha provocado que su obra haya sido recibida como una exitosa evolución de la farsa británica o francesa del siglo XIX. ¿Pero dónde encontramos su carácter queer? Además de haber servido de modelo para algunas de las obras de Oscar Wilde, como es el caso de The Importance of Being Erneast (Ramos, 2003), hay que señalar que uno de los temas más recurrentes en su producción se corresponde con el de los conflictos de pareja. A menudo, la acción se traslada al dormitorio u otro espacio privado de la casa donde una pareja descubre su frustración ante la idealización del amor (por ejemplo en Le Système Ribadier, 1892). En este sentido, quisiéramos realizar un inciso. El hecho de que se cuestionen aspectos de la pareja fue visto, en muchas ocasiones, como una amenaza al modelo patriarcal. En el teatro, incluso, se llegó a pensar que esto llevaba a una incuestionable enunciación homosexual desestabilizadora de las convenciones de la sexualidad común. Desde este prisma, escribía el crítico teatral Howard Taubman en 1961, alertando de ejemplos de escritura que actuaban de este modo. Proponía una serie de claves sobre las que había que fijarse cuidadosamente:

Atención al personaje masculino que es joven, atractivo, distante y arrogante de modo neutro... [...] Cuidado con el marido que no ha tocado a su mujer desde hace varios años. Cuidado con la mujer a la que el marido no ha puesto la mano encima en varios años. [...] Atención a la esposa repugnante que transforma la relación marital en algo horrible, relationship. (citado en Mira 1994, 99)

Supone una llamada de atención hacia ciertas prácticas teatrales en las que la institución matrimonial era cuestionada en favor de un conjunto de relaciones afectivas más complejo y libre, donde lo lúdico tenía una importancia esencial. Si bien esta lectura que realizamos de las farsas de Feydeau puede parecer ingenua, no hay que olvidar que en el teatro de las décadas de 1950 y 1960 la homosexualidad aún no era descrita, precisamente, a partir de elementos sexuales (Mira 1994, 112), sino a través de elementos velados, cuyo desciframiento era posible para una comunidad queer. Los rasgos señalados por Taubman podrían perfectamente ser aplicados a la obra La gata sobre el tejado de zinc caliente, de Tennesee Williams, en la que el protagonista rechaza "a su esposa, además, para refugiarse en el recuerdo idealizado de la noble amistad o camaradería masculina mantenida en su día con otro atleta, Skipper" (Gilabert 2011, 22-3).

Brick vive un turbulento momento afectado por el suicidio de su amigo Skipper. Aunque este no aparece en ningún momento en el escenario, se convierte en el centro de la obra, ya que su ausencia es determinante para que el drama se desarrolle. A pesar de que no se explicite el carácter homosexual de la relación entre ellos, este planea durante toda la obra. La presencia de personajes homosexuales ausentes o muertos se hizo frecuente a lo largo de la producción dramática de los tres primeros cuartos del siglo XX. El público aceptaba diferentes orientaciones o identidades sexuales siempre que estuviesen en off, especialmente si estos personajes se habían suicidado atormentados. Suponía un ajusticiamiento moral que calmaba a los espectadores ante la incertidumbre que les provocaba ver realidades sexuales diferentes de las aceptadas en la sociedad. Este tipo de comportamiento es especialmente notable a lo largo de la producción de Tennessee Williams: Un tranvía llamado deseo, La gata sobre el tejado de zinc y De repente, el último verano (Mira 1994, 130-131). 
La obra del escritor sureño fue determinante en la deriva de la filmografía de Almodóvar, especialmente cuando hizo irrupción el melodrama como parte de su discurso fílmico. Si a esto sumamos su sensibilidad queer, vemos cómo supuso un gran impacto descubrir su obra. Suponía vislumbrar una homosexualidad latente a través de ese código compartido ya comentado. En Williams, es evidente que podemos hablar de un teatro "que ratifica o autoriza una lectura homoerótica o bien que discursiviza una mirada homosexual" (Ceballos Muñoz 2004, 138). Un ejemplo claro lo hallamos en las hermanas Dubois de Un tranvía llamado deseo y su deseo de alcanzar el cuerpo de Stanley, erotizado plenamente al despojar Williams a su personaje de hondura intelectual alguna. Esto causó cierto escándalo, ya que esa objetualización de Stanley fue vista como indicio de una enunciación queer:

The blatant scandal of A Streetcar Named Desire (1947), initially, was its depiction of fema-

le desire. The gaze with Blanche and Stella direct at Stanley seemed to exude an extraordinary, even perverse, energy. Hence, in part, the supposition that this gaze must come from a gay man; women, it is (or was) imagined, are modest. ${ }^{3}$ (Sinfield 1999, 189)

Resulta muy interesante también el diseño del personaje de Blanche Dubois. Alan Sienfield alude a la influencia del psicoanálisis en Williams, especialmente en la creación de sus personajes femeninos: "They are given to hysterical sexual repression, which renders them alternately frigid and nymphomaniac" (recurren a la represión sexual histérica, lo que las representa unas veces como frígidas y otras como ninfómanas) (195-196). Esto, que podría extenderse al cine de Hitchcock y su obsesión por la figura de las rubias frías y distantes, no supone más que acudir a un catálogo de problemas psicológicos tamizados por la teoría freudiana para tomarlos como base en la construcción de los personajes femeninos, piénsese en la pieza de Williams De repente, el último verano, la obra donde la homosexualidad se hace más explícita y donde el psicoanálisis aparece, incluso, en la diégesis. Si revisamos el cine de Almodóvar, vemos cómo esta misma tendencia es palpable en su filmografía, con el personaje de Sexilia de Laberinto de pasiones como principal ejemplo. A pesar de esta coincidencia con el teatro de Williams, hemos de reconocer que, en la caracterización psicológica de Sexilia, la influencia le llegó del director de cine inglés y su película Marnie, la ladrona (Marnie, Alfred Hitchcock, 1964).

Lo que es indudable, como ya apuntamos, fue la influencia del teatro melodramático del director sureño. Y lo más importante, la forma en que fue consumido, especialmente cuando sabemos que estas obras no fueron apenas representadas en España hasta la década de 1990: ${ }^{10}$ el teatro de Williams llegaría mediante el discurso del cine clásico. ${ }^{11}$ El alto potencial intermedial de estos melodramas, como recientemente ha demostrado Marcie Frank (2013), fue esencial en la asimilación de este modelo por parte del director manchego. Liz Taylor, Marlon Brando, Paul Newman, Katherine Hepburn o Ava Gardner pondrán voz y rostro a sus atormentados personajes. Estamos hablando de películas como Un tranvía llamado deseo (A Streetcar named Desire, Elia Kazan, 1951), La gata sobre el tejado de zinc (Cat on a Hot Tin Roof, Richard Brooks, 1958), De repente, el último verano (Suddenly, Last Summer, Joseph L. Mankiewicz, 1959), Dulce pájaro de juventud (Sweet Bird of Youth, Richard Brooks, 1962) o La noche de la iguana (The Night of the Iguana, John Huston, 1964). 
Ya en el temprano debut de Almodóvar con Pepi, Luci, Bom y otras chicas del montón, podemos encontrar referencias a Williams. En concreto, en la escena en la que una mujer barbuda discute en su dormitorio con su marido, quejándose del tiempo que llevan sin hacer el amor. "Hace cuarenta días y cuarenta noches que no jodemos, y yo estoy que estallo, como una gata sobre un tejado de zinc," le reprochará la esposa. No solo en el texto y en la conexión argumental con la obra de Williams vemos relaciones, sino también con el vestuario de ella. Viste una elegante bata de seda que remite al glamour del Hollywood clásico, y que nos recuerda a la Liz Taylor de la película de Richard Brooks. Pero será en Todo sobre mi madre, con la puesta en escena de Un tranvía llamado deseo, cuando rinda su homenaje más sentido al director de Misisipi al poner en escena y filmar fragmentos de esta obra, así como al integrar su argumento dentro de la narración principal.

\section{UN SENTIMENTALISMO CAMP (JeAn Cocteau)}

El sentimentalismo es otro rasgo asociado a lo queer que está presente tanto en Williams como en Almodóvar. Supone un distanciamiento de la masculinidad tradicional al transgredir el comportamiento que se le presupone a este sexo. Este sentimentalismo, visto como contrario a la virilidad, podría ser extensible también a otra obra teatral presente de forma repetida en el cine del director español, La voz humana, del autor francés Jean Cocteau, cuya personalidad y obra sería calificada como camp por Susan Sontag $(1964,359)$. El sentimentalismo así se mostraba opuesto a la idea de lo varonil:

Al estudiar las relaciones, en la representación, entre homosexualidad y virilidad, hemos apuntado cómo la homosexualidad se construía en el discurso especialmente a partir de elementos descartados en el mito de la identidad viril. Uno de estos elementos descartados, quizá uno de los más importantes, es el sentimentalismo. No solo los hombres no lloran, sino que los hombres nunca deben dejarse arrastrar por el sentimentalismo. (Mira 1994, 154)

Recordemos que se trata de un monólogo breve para una sola actriz, en el que tiene que escenificar con desesperación un duro trance: el hombre al que ama, y que la ha abandonado, se va a casar con otra mujer. En el escenario, solo aparece una cama, la intérprete y un teléfono que tendrá un lugar clave en la obra, ya que la protagonista mantendrá durante toda la representación una conversación telefónica con él, repleta de interrupciones debidas a fallos técnicos. ${ }^{12}$ Una fuerte dosis de sentimentalismo inunda la propuesta exigiendo una interpretación desgarrada por parte de la intérprete que, según las didascalias del propio autor, tiene que comportarse como un animal herido, cuya sangre debe inundar la escena. ${ }^{13}$

Esta obra es usada en el cine de Almodóvar siguiendo diferentes criterios de adaptación. ${ }^{14}$ Como ejemplo mencionaremos La ley del deseo (1987), donde se opta por representar un par de fragmentos dentro de la diégesis fílmica. Tina, transexual y hermana de Pablo Quintero, el director de la obra, es la protagonista, que aguarda cerca del teléfono la llamada de su examante. Al inicio de la escena, Ada, la hija de Tina, cruza el escenario de izquierda a derecha subida a unos raíles mientras interpreta el playback del Ne me quitte pas, de Jacques Brel, en la versión de la artista brasileña Maysa Matarazzo. El patetismo de la escena es incrementado con el acting de Tina, quien, enrabietada, irá destrozando el decorado con un hacha. Pero no solo se procederá a este recurso, sino que la propia idea de abandono estará presente en la biografía de los personajes de estas dos mujeres que actúan como actrices sobre las tablas. Se produce 
así el refuerzo de una teatralidad que trasciende la escena para afectar la vida privada de los personajes que escenifican la obra. Estaríamos hablando de un ejemplo de teatralidad como especularidad compleja (Pérez 2010, 48), ficción en segundo grado que actúa, además de espejo, de refuerzo de lo narrado. Y esto no solo afecta a Tina y a Ada, sino que es extensible a toda la película, en cuanto esta se muestra como una sucesión de dolorosos abandonos: Pablo por Juan, Antonio por Pablo, Tina por su padre y más tarde por la madre de su hija, y Ada por su madre. Una serie de acontecimientos que van marcando el aire de desamparo que inunda todo el filme, que viene secundado, además, y de forma eficaz, por la presencia en la banda sonora de diferentes temas musicales — como los boleros o el tema Ne me quitte pas-que contribuyen a una sentimentalidad doliente.

Son diferentes las formas en las que Cocteau se relaciona con lo queer. Ya hemos citado cómo Susan Sontag vislumbraba en su personalidad y obra una notable sensibilidad camp, derivada, entre otras cosas, del llamativo tono kitsch de sus producciones. Podemos ver esto de forma muy evidente en películas como La bella y la bestia (La belle et la bête, 1946). Este filme ejemplifica muy bien uno de los elementos más controvertidos de su obra, el punto de vista sobre el amor y la sexualidad (Sheaffer-Jones, 2002): "The advocacy of a female subjectivity (the story is told from Belle's point of view) and the notion of equality, so present in this film, ran very contrary to the prevailing message of films dealing with sexual relations in the late-1940s and early-1950s"4 (Hayward 1996, 47).

Susan Hayward va más allá en la interpretación de este punto de vista femenino, y alude directamente a esta película como un ejemplo indudable de amor homoerótico. Lo mismo podría decirse de Orfeo (Orphée, 1950), adaptación de la obra teatral homónima de 1925, donde Cocteau filma imágenes de un homoerotismo notable, como cuando el protagonista se refleja en un espejo y acaricia con su mejilla la superficie. O hacia el final, con su muerte, cuando es sostenido a modo de una pietá gay: "Heurtebise grabs Orpheus from behind, covering his eyes and mouth (but not his nose), and Orpheus struggles in a singularly theatrical way until he finally goes limp" (Heurtebise agarra a Orfeo desde atrás, cubriendo sus ojos y boca pero no su nariz-, y Orfeo lucha de una manera particularmente teatral hasta que finalmente se desploma) (Desilets 2012, 295). Si echamos un vistazo a La ley del deseo, podemos ver cómo estos dos momentos tienen su réplica. Lo podemos observar en el inicio de la película, cuando un joven es dirigido en una escena erótica y se le ordena besarse en un espejo, y en el plano final, cuando Pablo sostiene el cuerpo sin vida de Antonio. Si en la película de Cocteau el subtexto homosexual era más o menos latente, en la película de Almodóvar se convierte en explícito. A este respecto nos es especialmente interesante su arranque ya citado, por la manera en la que articula y manipula el mecanismo espectatorial. En esta escena, el espectador toma el punto de vista del director autoritario, cuya voz se oye en off. Las miradas que el joven lanza a la cámara interpelan directamente al público, que es identificado como un espectador homosexual. Así contemplará, con esta mirada queer, al joven mientras se va desnudando y acariciando, transfigurado ya en un evidente objeto de deseo erótico. Tras esta inmersión abrupta en el mundo homosexual desde el inicio, el pasional devenir de los protagonistas de la película será recibido sin reticencias. La enunciación queer es asumida sin miedos.

En la obra de Cocteau, es posible, además, establecer diferentes conexiones con otros autores considerados queer. En 1909, con Le portrait surnaturel de Dorian Gray, adapta a la escena la novela El retrato de Dorian Gray, de Oscar Wilde, obra que anticipaba una mirada queer décadas antes de que se produjesen los movimientos de liberación sexual (Schulz 2011). 
Pero es, especialmente, con su coetáneo Williams con quien podemos encontrar relaciones de reciprocidad en su producción dramática (Michiels y Collard 2013). Cocteau adapta en 1949 al francés, como ya hiciera con la obra citada de Wilde, Un tranvía llamado deseo, versión que alcanzaría un gran éxito tras su estreno parisino. Pero es el interés por el mito de Orfeo el que une principalmente a ambos autores. Williams realizó su propia versión del mito tanto en Battle of Angels (1940) como en la posterior reelaboración de esta obra, en Orpheus Descending (1957). En estas piezas dramáticas, así como en el Orphée teatral de Cocteau, Orfeo no es músico, sino escritor. Pero no solo en este uso del mito coinciden, sino también en el tratamiento físico en la caracterización de los personajes masculinos. Es aquí donde se aproximan sendos universos personales, en torno a una sensibilidad queer: "There is also a sexual world. Cocteau's and William's presumed homosexuality providing an umpteenth echo of both playright's facination with physicality" (existe también un mundo sexual. Una presunta homosexualidad de Cocteau y William que proporciona un interminable eco de la fascinación de los dos dramaturgos con la fisicidad) (Michiels y Collard 2013, 509).

\section{LA PERSONIFICACIÓN DEL DESEO HOMOSEXUAL EN LORCA Y ALMODÓVAR}

Esta misma importancia dada a la corporalidad masculina puede ser advertida en el teatro más vanguardista de García Lorca. Enrique Álvarez (2010) vislumbra, además, una asociación con la muerte en estas obras, algo que podemos ver, por ejemplo, en la escena segunda de El público con los personajes de Pámpanos y Cascabeles, donde el amor erótico es frustrado y condenado a la prostitución ante la imposibilidad de ser vivido abiertamente (Pedrosa 2001).

La indagación acerca del amor, el deseo y la identidad presente en El público anuncia las teorías

de género y el movimiento "queer" de la década del noventa. Enfatiza la transformación de los personajes, la deconstrucción de las identidades, la exploración por las diferentes manifestaciones del amor más allá de los márgenes de la cultura sexual dominante. (Iribe 2011,4)

Parte de la crítica y el público ha realizado lecturas queer del teatro de Lorca, poniendo su atención para justificarlo en la presencia de personajes femeninos frustrados, que eran usados para enmascarar su homosexualidad. Sería el caso de Paul Julian Smith, para quien "the rebellious heroines of Lorca's drama are 'really' men, disguised or displaced figures of the author's own sexual opression" (las rebeldes heroínas de las obras de Lorca son "en realidad" hombres, figuraciones disfrazadas o desplazadas de la propia represión sexual del autor) $(1989,110)$. En este sentido, lo afirma Maria Elena Polydorou, quien lo conecta, además, con la obra de Tennessee Williams:

Like Lorca, it is claimed Williams often used women in his plays as representations of hidden and frustrated homosexual desires [...] Lorca's and William's homosexual expression can go beyond the female characters and spill into those of the male (i.e. male characters with gay sensibilities or camp qualities). ${ }^{5}(2012,106)$

La investigadora centra su análisis en la trilogía rural formada por Yerma, Bodas de sangre y La casa de Bernarda Alba. En esta última obra, la frustración de las hermanas sería interpretada como símbolo de la propia represión sexual del escritor granadino. El ambiente claustrofóbico y enrarecido - muy presente también en las obras teatrales de Williams, en ese húmedo y caluroso sur- sería interpretable en este sentido y refuerza este sentimiento de aprisionamiento. 
El teatro de Lorca adquiriría un reconocimiento notable con la caída de la Dictadura y alcanzaría un gran auge en su representación, especialmente a partir de mediados de la década de 1980. Si bien en un principio fue reconocido solo por sus méritos en la renovación poética y teatral (Martínez Expósito 2011, 28), la situación variaría y su carácter político y queer comenzaría a ser reivindicado: "During the years 1986-89 there was a veritable explosion of works on Lorca, due to the 50th anniversary of the poet's death. Many of the following deal with Lorca's homosexuality" (entre los años 1986 y 1989 hubo una auténtica explosión de trabajos sobre Lorca debido al 50 aniversario de la muerte del poeta. Muchos de ellos trataban acerca de la homosexualidad de Lorca) (Sahuquillo 2007, 50). Al igual que en el caso de La bella y la bestia, de Cocteau, la focalización femenina subvertía el statu quo dominante y, además, a través de dicha focalización se atendía a una serie de cuestiones que en ese momento les eran vetadas a las mujeres. La sexualidad se convierte en parte del discurso de una clase femenina oprimida por su entorno:

In the theatre work of this male writer, García Lorca, we are faced with a peculiar line up of characters who behave in ways that women aren't supposed to. Above all, they love and desire in ways women are denied. Associated with these women are a range of singularly unimpressive men who fail miserably to make their masculine presence felt, and are eventually elided altogether. It is no surprising that a queer writer should challenge conventional gender performance. In traditional terms, women who wish to be the subjects of desire and men who wish to be the objects are getting the prescribed correspondence between their gender characters he authored, have their gender behavior all wrong. Interrogating gender is a vital task for García Lorca. ${ }^{6}$ (McDermid 2007, 3)

La tragedia presente en las películas de Almodóvar como La ley del deseo y la focalización femenina de la gran mayoría de sus películas aproximan los horizontes creativos de estos dos creadores españoles. Es comprensible que sus producciones hayan sido comparadas reiteradamente, ya desde una perspectiva queer (como es el caso que nos ocupa), ya desde puntos de vista tan variados como puede ser el de la tauromaquia (Hernández 2001, 2002). Lorca y Almodóvar tienen también en común haber puesto la atención en una tradición localista — que se corresponde con el imaginario español_ para realizar un cine o teatro de alcance universal, usando para ello técnicas propias de las vanguardias de sus respectivos momentos históricos. No es casual, por tanto, que Almodóvar decidiera usar una obra basada en Bodas de sangre de Lorca para reforzar el sentimiento trágico de Todo sobre mi madre. Además de la indiscutible valía de la obra, la vehiculización del dolor y el sufrimiento en esta obra a través de una mujer suponía un gran aliciente. Era una forma de expresión del yo poético a través de una enunciación discreta queer.

Paul Julian Smith ha dedicado parte de su producción académica a analizar la obra de estos autores enlazando la focalización presente en un autor y en otro. El hecho de que la parte principal de sus producciones estén protagonizadas por mujeres les ha llevado a ser analizados siguiendo parámetros similares. Si bien no es nuestra intención definir aquí una focalización exclusivamente femenina, sí podemos hacer uso de las palabras de este investigador para poner de relieve las diferentes vías de conexión presentes en sus obras,

and that both do so not by presenting positive images of women, but by attempting strategies of representation which displace, momentarily at least, conventional ways of seeing. By placing the pleasure of the woman's look at the centre of their theatre and cinema, García Lorca and Almodóvar may alter the standard of vision, of what can be seen. ${ }^{7}(1996,19)$ 
Además del caso de El público, podríamos acudir a La casa de Bernarda Alba, donde el deseo que sienten las hermanas tiene su reflejo en el cine del director manchego en el sufrimiento amoroso de la madre superiora por Yolanda. Si en el primer caso el elemento masculino quedaba deliberadamente fuera de escena, en el segundo se produce una interesante mutación. Dentro del ambiente claustrofóbico recreado, la monja sentirá un deseo irrefrenable por la vedete, que será reforzado con la inclusión del bolero para remarcar su pasión. Si en la obra de Lorca podemos adivinar una frustración amorosa que enmascara una enunciación queer, en el segundo caso el lesbianismo es tratado con total normalidad, fruto de la liberación sexual que se va desarrollando en España tras la muerte del dictador Franco y la apertura a la democracia. El contexto sociopolítico del momento actúa, así, como condicionante clave en la técnica narrativa al permitir a los autores exponer una enunciación queer de una manera más o menos evidente, dependiendo de las consecuencias negativas que esto podría acarrearles.

\section{CONCLUSIONES}

Vemos, pues, cómo es posible trazar una línea de continuidad entre el teatro queer y la obra de Almodóvar, en cuanto vemos cómo se adoptan algunos de sus principales presupuestos narratológicos y estéticos. Y no solo se produce esto con la inclusión de intertextos mediante diferentes recursos, o bien la cita, o bien la alusión (Genette 1982, 10), sino que podríamos hablar, incluso, de una intertextualidad en un sentido más amplio, como el otorgado por Julia Kristeva al término, marco referencial común donde lo queer se establece como categoría concomitante a diferentes prácticas artísticas, en este caso el teatro y el séptimo arte.

Sin lugar a dudas, el repertorio cultural disponible durante los años de formación como espectador de Almodóvar le hizo asumir ciertas prácticas cinematográficas, y artísticas en general, donde la homosexualidad era presentada de forma oculta, aunque veladamente manifiesta para una comunidad gay que era capaz de identificar las claves de enunciación homosexual presentes en esas obras. Se abría así el paso a la relectura de gran parte de la historia del arte, un discurso silenciado para poder sobrevivir a un entorno donde la heteronormatividad era una constante aparentemente irrevocable. En el cine, la enunciación masculina propia del modo de representación institucional perdía su carácter heterosexual y asumía nuevos valores expresivos (Burch 1999).

Si en autores como Williams o Cocteau lo homosexual permanecía en un estado de discreta latencia, con Almodóvar observamos cómo la explicitud de las diferentes variantes sexuales encuentra perfecto acomodo en su cine y se convierte así en uno de los referentes para la subcultura gay, un ámbito que cada vez más, y gracias a autores como el director español, ha visto su "salida del armario" del ambiente cultural underground. El éxito comercial de películas suyas como Todo sobre mi madre (con la presencia de transexuales y una pareja de lesbianas) o de La piel que habito (donde el deseo sobre la identidad sexual es ambiguo dado el carácter de transexual forzado del personaje principal) viene así a demostrarlo. La enunciación queer se realiza así de forma desprejuiciada y libre, de acuerdo con lo que debe ser la creación estética, y demuestra que las sexualidades periféricas, como lo definiría Foucault, son discursos plenamente legítimos apoyados por prácticas artísticas, como este tipo de películas y obras de teatro con una mirada narrativa marcadamente queer. 


\section{NOTAS}

1 "Queer", término usado normalmente para burlarse y vilipendiar a las personas homosexuales, fue reapropiado, entre otros, por Queer Nation como un abrigo para celebrar, en vez de castigar, la diferencia respecto de la "norma" en un momento en el que la opresión y la violencia implícita de esa norma era clara e innegable.

2 Quizá el talento más destacable de Georges Feydeau fuera hacer que lo ilógico funcionara a la perfección. El desorden y la irracionalidad adquieren validez en sus obras, sin estar sujetas a las leyes de lo probable o a un escrutinio analítico. Esto es posible gracias a los abundantes mecanismos farsescos de sus comedias.

${ }^{3}$ Lo realmente escandaloso de Un tranvía llamado deseo (1947), en un principio, fue su retrato del deseo femenino. Las miradas que Blanche y Stella dirigen a Stanley parecían desprender una extraordinaria, e incluso perversa, energía. De ahí que, en parte, se supusiera que esta mirada venía de un hombre gay; las mujeres, se imagina (o imaginaba), son más recatadas.

${ }^{4}$ La defensa de una subjetividad femenina (la historia se cuenta desde el punto de vista de Bella) y la noción de igualdad, tan presente en esta película, se oponen al mensaje prevalente de los filmes que trataban las relaciones sexuales a finales de la década de 1940 y a comienzos de la década de 1950.

${ }^{5}$ Como sucede con Lorca, también de Williams se dice que usaba mujeres en sus obras como representaciones de sus ocultos y frustrados deseos homosexuales [...] La expresión homosexual de Lorca y Williams puede ir más allá de los personajes femeninos y extenderse hacia los masculinos (por ejemplo los personajes masculinos con sensibilidades gais o tal vez camp).

${ }^{6}$ En el trabajo teatral de este escritor, García Lorca, nos encontramos ante una peculiar serie de personajes que se comportan de una manera que no se les presupone a las mujeres. Sobre todo, aman y desean de formas que les son negadas a las mujeres. Vinculados a estas mujeres encontramos una serie de hombres mediocres que fracasan estrepitosamente en hacer sentir su presencia masculina, y son al final ignorados totalmente. No sorprende que un escritor queer pudiera cuestionar los roles de género convencionales. Desde un punto de vista tradicional, las mujeres que deseaban ser sujetos de deseo y los hombres que querían ser objetos de este están contradiciendo la establecida correspondencia entre sexo y género. Cuestionar el género es una tarea vital para García Lorca.

${ }^{7} \mathrm{Y}$ eso sin presentar imágenes positivas de las mujeres, sino ensayando estrategias de representación que desplazan, momentáneamente al menos, las formas convencionales de ver. Al situar el placer de la mirada de la mujer en el centro de su teatro y de su cine, García Lorca y Almodóvar pueden alterar las normas de visión, de lo que puede ser visto.

\section{NOTAS FINALES}

1. En este mismo sentido, aunque sin realizar una adscripción concreta a ningún movimiento, se manifiesta Alfredo Martínez Expósito: "Ser hombre o mujer, gay o lesbiana, trans o drag, homosexual o heterosexual se estaba quedando estrecho para muchas y muchos de los sujetos que hartos de sus etiquetas debían luchar por sus derechos a las diferencias, contra el entramado siempre confuso al priorizar una de esas identidades frente a las otras en función del contexto o de la posibilidad que ofreciera la inserción en un colectivo determinado" $(2009,40)$.

2. El Queer Nation surge en 1990 “durante una manifestación del Orgullo gay en Nueva York. Su manifiesto 'odio a los hetero' se difundió rápidamente en San Francisco y otras grandes ciudades de EEUU" (44). Suponía una reacción contra la imagen neutra que se había querido dar por parte del colectivo LGBT (lesbianas, gais, transexuales y bisexuales) con la intención de ser aceptados dentro del mainstream heterosexual, de ahí esa llamada a la protesta "políticamente incorrecta".

3. Juan Carlos Hidalgo aporta una definición más amplia, a pesar de reducir su estudio a la escena teatral británica de la década de 1980. Para él puede ser tanto el teatro escrito o adaptado por un homosexual como el representado por homosexuales, así como el que está dirigido a este colectivo o pueda hacer alusión a temas pertinentes a ellos $(1994,129)$.

4. Aunque no nos detendremos en la enunciación queer de las películas de Pedro Almodóvar, hay que admitir que el cuerpo masculino se convierte en objeto de deseo en muchas de sus películas que marca históricamente con sus primeras películas una ruptura con la tradición cinematográfica española, donde solo la filmografía 
de Eloy de la Iglesia se constituía en un modelo de apreciable interés en este sentido: "Things have certainly changed since then. The arrival of Pedro Almodóvar (and, before him, Eloy de la Iglesia [...]) onto the Spanish cinema scene introduced a male homosexual perspective in wich the display and objectification of the male body was much more commonplace" (indudablemente las cosas han cambiado desde entonces. La llegada de Pedro Almodóvar - $y$, antes de él, de Eloy de la Iglesia [...] - a la escena cinematográfica española introdujo una perspectiva homosexual masculina en la que la exhibición y cosificación del cuerpo del hombre se fue haciendo cada vez más común) (Fouz-Hernández y Martínez-Expósito 2007, 13). Este novedoso enfoque adquirirá mayor importancia cuando además dote de psicología y desarrollo dramático completo a sus personajes homosexuales, especialmente con La ley del deseo (Martínez-Expósito 2004, 241).

5. Dentro del segundo caso, sin lugar a dudas el más llamativo, Sinfield señala Angels in America, de Tony Kushner, obra para él clásica de la historia del teatro estadounidense y que marcaba un giro en la identidad norteamericana, capaz de aceptar los diferentes tipos de orientación sexual sin especiales dramas.

6. Musicales recientes como Priscilla, reina del desierto (Priscilla, Queen of the Dessert - The Musical, Stephan Elliott y Allan Scott, 2006) son un claro indicio de esto, donde lo queer es asociado a una teatralidad basada en el artificio. Este musical australiano, además, muestra un ejemplo claro de intermedialidad, ya que su origen tiene lugar unos años antes cuando fue creada su historia directamente para el cine con Las aventuras de Priscilla, reina del desierto (The Adventures of Priscilla, Queen of the Desert, Stephan Elliot, 1994).

7. A pesar de ser un extracto de la crítica al estreno en el West End londinense de la versión teatral de Mujeres al borde de un ataque de nervios, nos resulta muy atractivo este fragmento por cómo menciona algunas claves del teatro de Feydeau presentes en el cine de Almodóvar: "But most of the action takes place in Pepa's flat, which gradually fills up with people in the manner of a Feydeau farce: not only Ivan's deranged, gun-toting exwife and randy son, with his future bride, but a flaky, suicide-prone model and a couple of cops who unwittingly down Pepa's spiked gazpacho. It's all screwball fun with an undertow of rueful sadness" (Pero la mayor parte de la acción tiene lugar en el piso de Pepa, que gradualmente se llena de gente igual que en una farsa de Feydeau: no solo la perturbada y armada exmujer de Iván y su hijo salido con su futura esposa, sino también una modelo extraña y con tendencia al suicidio y un par de policías que sin darse cuenta se zampan el gazpacho condimentado de Pepa. Es todo un divertimento estrafalario con un regusto a tristeza) (Billington 2015). Véase también la crítica de Philip French para The Guardian (2013) donde menciona a Feydeau en alusión a la comedia clásica norteamericana.

8. Son, especialmente, destacables sus farsas en un solo acto, como en la trilogía formada por los títulos Feu la mère de madame! (1908), On purge bébé! (1910) y Mais n'te promène donc pas toute nue! (1911).

9. Si ya la comedia ha sido tradicionalmente un género que ha carecido del debido reconocimiento académico, debido a que gran parte de los ejemplos del teatro cómico tenían como único objetivo arrancar la carcajada del espectador sin trascender este mero acto lúdico, la farsa vería cómo su recepción se haría en un sentido aún más peyorativo: "Traditionally farce was viewed as a somewhat vulgar, inferior genre, whose only purpose was to provide vacuous diversion for vacant minds" (Tradicionalmente la farsa era vista como un género menor y algo vulgar, cuyo único propósito era proporcionar una diversión vacua para mentes vacías) (Farrell 1995, 307).

10. La latencia homosexual seguro que se encontraba detrás de la desafección del teatro español hacia las obras de Williams. El tema de la sexualidad seguiría siendo tabú en ciertos sectores, a pesar de la abolición de la censura con la Transición. Estas palabras de Ángel Facio son bastante elocuentes en este sentido: “Yo estoy convencido de que si se negaron durante cuatro años a que yo montara otra vez en España La casa de Bernarda Alba, fue porque en el hecho de que el personaje central lo interpretase un hombre, veían una alusión al mundo homosexual de Federico. Y ellos han estado años tratando de ocultar la homosexualidad de Federico, cuando tenían que haberlo aceptado" (citado en Cabal y Alonso de Santos 1985, 241).

11. "No podía evitar ser más sensible a la voz de Tennessee Wiliams surgiendo de los labios de Liz Taylor, Paul Newman o Marlon Brando, que al susurro pastoso y baboso de mi Director Espiritual." [...] Lo que no sabía era que, décadas más tarde, algunas de las imágenes proyectadas en las pantallas de mi niñez llevarían mi firma y estarían marcadas por aquellas primeras películas donde T. Williams era mi auténtico director espiritual" (Almodóvar, citado en Strauss 2000, 134).

12. Recordemos que la obra fue estrenada en la Comédie Française y escrita para la acriz Berthe Bovy en 1930, cuando la telefonía aún no había logrado alcanzar un correcto desarrollo técnico. Las conversaciones cruzadas entre diferentes usuarios de la línea, y la presencia al otro lado del hilo telefónico de la operadora, serán solo algunas de las dificultades que se interponen entre la protagonista y su amante. Una comunicación imposible que contribuye a crear ese aire de desasosiego que inunda la obra. 
13. "El autor quisiera que la actriz diese la impresión de sangrar, de perder su sangre, como un animal que cojea; de que el acto termina en una habitación llena de su sangre" (Cocteau 1962, 42).

14. Otro caso interesantísimo sería el realizado en Mujeres al borde de un ataque de nervios (1988), donde el teléfono se constituye en un elemento visual clave y el tema del abandono está presente en el argumento de la película. Dada la brevedad de este trabajo, no lo abordaremos.

\section{REFERENCIAS}

Álvarez, Enrique. 2010. Dentro/fuera: el espacio homosexual masculino en la poesía española del siglo XX. Madrid: Biblioteca Nueva.

Billington, Michael. 2015. "Women on the Verge of a Nervous Breakdown review: West End musical is screwball fun". The Guardian, 12 de enero. https://www.theguardian.com/stage/2015/jan/12/ women-on-verge-of-nervous-breakdown-review

Brewster, Ben. 2001. “The Circle: Lubitsch and the Theatrical Farce Tradition." Film History 13 (4): 372-389.

Burch, Nöel. 1999. El tragaluz del infinito: contribución a la genealogía del lenguaje cinematográfico. Madrid: Cátedra.

Cabal, Fermín y José Luis Alonso de Santos. 1985. Teatro español de la década de 1980. Madrid: Fundamentos.

Casmus, Mary I. 1980. "Farce and Verbal Style in the Plays of Joe Orton". Journal of Popular Culture 13 (3): 461-468.

Ceballos Muñoz, Alfonso. 2004. "Representación" de la identidad gay en la obra dramática de Terrence McNally. Valencia: Universidad de Valencia.

Cocteau, Jean. 1962. “La voz humana." En Cuatro monólogos: El bello indiferente, La voz humana, La farsa del castillo, El fantasma de Marsella, 34-59. Madrid: Alfil.

Desilets, Sean. 2012. “Cocteau's Female Orpheus". Literature Film Quaterly 40 (4): 288-300.

Devine, Maureen. 1986. "Acceptable Madness in Georges Feydeau's Going to pot (On purge bébé)." Thalia 9 (1): 22-30.

Farrell, Joseph. 1995. "Fo and Feydeau: Is Farce a Laughing Matter?". Italica 72 (3): 307-322.

Foucault, Michel. 1998. Historia de la sexualidad I: La voluntad de saber. Madrid: Siglo XXI.

Fouz-Hernández, Santiago y Alfredo Martínez-Expósito. 2007. Live Flesh: The Male Body in Contemporary Spanish Cinema. Londres: Tauris.

Frank, Marcie. 2013. "At the Intersections of Mode, Genre, and Media: A Dossier of Essays on Melodrama". Criticism: A Quarterly for Literature and the Arts 55 (4): 535-545.

French, Phili. 2013. "Chaos Reigns in Business Class in Pedro Almodóvar's Slight Yet Droll Commentary on Post-Crash Spain." The Guardian, 5 de mayo. https://www.theguardian.com/ film/2013/may/05/im-so-excited-review

Genette, Gérard. 1989. Palimpsestos: la literatura en segundo grado. Madrid: Taurus.

Gilabert Barberà, Pau. 2011. “Ecos contemporáneos del éros griego." En Homoerotismos literarios, editado por Rodrigo Andrés González, 17-38. Madrid: Icaria.

Hall, Donald E. 2003. Queer theories. Nueva York, Hampshire: Palgrave MacMillan.

Hayward, Susan. 1996. "La belle et la bête". History Today 46 (7): 43-48.

Hernández, María. 2001. "La tauromaquia como espacio transgresor en Lorca y Almodóvar". Cuadernos de Aldeeu 17 (1): 75-90.

— 2002. "El deseo y la tauromaquia en Federico García Lorca y Pedro Almodóvar: ¿género, ideología o fuerza irracional?". Romance Review 12: 59-67. 
Hidalgo, Juan Carlos. 1994. Tendencias alternativas en el teatro londinense de los años 80. Valencia: Universidad de Valencia.

Iribe, Nora Gabriela. 2011. "Teatro bajo la arena: El público de Federico García Lorca". En Diálogos transatlánticos: Memoria del II Congreso Internacional de Literatura y Culturas Españolas Contemporáneas, editado por Raquel Macciuci. La Plata: Universidad Nacional de La Plata. http://congresoespanyola.fahce.unlp.edu.ar/ii-congreso-2011/actas-ii-2011/volumen-iii/ III05Iribe.pdf

Martínez-Expósito, Alfredo. Escrituras torcidas. Barcelona: Laertes, 2004.

- 2009. "Normalización y literatura 'queer'." En Seminario Teoría Queer: de la transgresión a la transformación social, 26-38. Sevilla: Fundación Centro de Estudios Andaluces.

- 2011. "La literatura gay española y el lugar de los estudios culturales". Lectora 17: 25-39.

McDermid, Paul. 2007. Love, Desire and Identity in the Theatre of Federico García Lorca. Woodbridge, Rochester: Tamesis.

Michiels, Laura y Christophe Collard. 2013. “Double Exposures: On the Reciprocity of Influence between Tennessee Williams and Jean Cocteau". Comparative Drama 47 (4): 505-527.

Mira, Alberto. 1994. ¿Alguien se atreve a decir su nombre? Enunciación homosexual y la estructura del armario en el texto dramático. Valencia: Universidad de Valencia.

Parshall, Peter F. 1981. "Feydeau's A Flea in Her Ear: The Art of Kinesthesic Structuring". Theatre Journal 33 (3): 355-364.

Pedrosa, José Manuel. 2001. "Pámpanos, cascabeles y la simbología erótica en El Público de Lorca". Teatro: Revista de Estudios Teatrales 13-14: 371-386.

Pérez Bowie, José Antonio. 2010. “La teatralidad en la pantalla: un ensayo de tipología”. Signa 19: 35-62.

Polydorou, Elena María. 2012. The Reception of Federico García Lorca and his Rural Trilogy in the UK and Spain after 1975. Birgmigham: University of Birmingham.

Ramos Gay, Ignacio. 2003. "Farsas, dobles y simetrías en Georges Feydeau y Oscar Wilde. De Monsieur Chasse! A The Importance of Being Earnest". En El texto como encrucijada: estudios franceses y francófonos, editado por Ignacio Iñarrea Las Heras y María Jesús Salinero Cascante, 375-388. Logroño: Universidad de La Rioja.

- 2006. "Rito y exorcismo social en la dramaturgia de Alan Ayckbourn". Espéculo: Revista de Estudios Literarios 33. http://www.biblioteca.org.ar/libros/152313.pdf

Sahuquillo, Álvaro. 2007. Federico García Lorca and the Culture of Male Homosexuality. Jefferson, North Carolina: McFarland y Company.

Salvato, Nick. 2010. Uncloseting Drama: American modernism and queer performance. New Heaven: Yale University Press.

Schulz, Dirk. 2011. Setting the Record Queer: Rethinking Oscar Wilde's "The Picture of Dorian Gray" and Virginia Woolf's "Mrs. Dalloway." New Brunswick, Londres: Transaction Publishers.

Sheaffer-Jones, Caroline. 2002. "Fixing the gaze: Jean Cocteau's La belle et la bête." Romanic Review 93 (3): 361-374.

Sinfield, Alan. 1999. Out on Stage: Lesbian and Gay Theatre in the Twentieth Century. New Haven, London: Yale University Press.

Smith, Paul Julian. 1989. The Body Hispanic: Gender and Sexuality in Spanish and Spanish American Literature. Oxford: Oxford University Press.

- 1996. Vision Machines: Cinema, Literature and Sexuality in Spain and Cuba, 1983-1993. Londres: Verso.

Sontag, Susan. 1964. “Notas sobre lo camp”. 1996. En Contra la interpretación, pp. 335-76. Madrid: Alfaguara.

Sontag, Susan. 1996. Contra la interpretación. Madrid: Alfaguara.

Strauss, Fréderic. 2000. Conversaciones con Pedro Almodóvar. Barcelona: Akal. 


\section{Cómo citar este artículo:}

Torre Espinosa, Mario de la. 2018. "Modelos de intermedialidad en la adaptación cinematográfica del teatro homosexual en el cine de Pedro Almodóvar". Cuadernos de Música, Artes Visuales y Artes Escénicas 13 (1): 117-133. doi:10.11144/javeriana. mavae13-1.mdid 